\title{
Distribution of trace elements in the marine sediments along the South China Sea, Malaysia.
}

\begin{abstract}
In order to complete having data base of elemental assessment of the east coast of Peninsular Malaysia marine sediments along the South China Sea coasts, trace elements are analyzed and their distribution in marine sediments is undertaken. The present study is done parallel with pervious study on elemental assessment of heavy metals, rare earth elements and actinides in the marine sediments of the east coast of Peninsular Malaysia. Thirty surface sediment samples were collected in this area, including regions of Kelantan, Terengganu, Pahang, Rompin and Johor Baharu. Multielemental analysis was carried out by instrumental neutron activation analysis and inductively coupled plasma atomic emission spectroscopy. In both cases methodology validation was performed by certified reference material analyses. For the surface elemental distributions the enrichment factor values, average I geo and $\mathrm{mC} \mathrm{d}$ values indicate that the trace elements of the surface sediments are uncontaminated in all sampling stations that are consistent with previous studies results of heavy metals, rare earth elements and actinides.
\end{abstract}

Keyword: ICP-AES,INAA; Marine sediments; South China Sea; Trace elements. 